\title{
Effect of pre-freeze semen quality, extender and cryoprotectant on the post- thaw quality of Asian elephant (Elephas maximus indicus) semen
}

\author{
Podjana Imrat $^{\mathrm{a}}$, Piyawan Suthanmapinanth ${ }^{\mathrm{b}}$, Kulnasan Saikhun ${ }^{\mathrm{c}}$, Sittidet Mahasawangkul ${ }^{\mathrm{d}}$, Edita \\ Sostaric $^{\text {a }}$, Pettisak Sombutputorn ${ }^{\mathrm{d}}$, Saran Jansittiwate ${ }^{\mathrm{d}}$, Nikorn Thongtip ${ }^{\mathrm{b}}$, Anuchai \\ Pinyopummin $^{\mathrm{b}}$, Ben Colenbrander ${ }^{\mathrm{a}}$, William V. Holt ${ }^{\mathrm{e}}$ and Tom A.E. Stout ${ }^{\mathrm{a}, \mathrm{f}}$ \\ ${ }^{a}$ Faculty of Veterinary Medicine, Department of Equine Sciences, Utrecht University, \\ Yalelaan 114, 3584 CM, Utrecht, The Netherlands \\ ${ }^{b}$ Faculty of Veterinary Medicine, Kasetsart University, Nakhonpathom 73140, Thailand \\ 'Institute of Molecular Biosciences, Mahidol University, Nakhonpathom 73170, Thailand \\ ${ }^{\mathrm{d}}$ National Elephant Institute, Forest Industry Organization, Lampang 52190, Thailand \\ 'Institute of Zoology, Zoological Society of London, Regent's Park, London, NW1 4RY, UK \\ fDepartment of Production Animal Studies, University of Pretoria, \\ Private Bag X20 Hatfield, Pretoria 0028, South Africa
}

Cryobiology 2013: 66: 52-59 


\begin{abstract}
Semen cryopreservation and artificial insemination (AI) are potentially valuable methods for supporting the breeding management of endangered species like the Asian elephant. Cryopreservation of Asian elephant semen has however proven problematic with respect to maintenance of both adequate semen quality and fertility post-thaw. In this study, nine ejaculates from three adult bulls were used to compare the influence of extender (TEST versus INRA96 ${ }^{\circledR}$ ) and penetrating cryoprotectants (3\% glycerol, 5\% glycerol and 4\% methylformamide) on postthaw semen quality. We demonstrate that not only the freezing process, but also the quality of the semen before freezing, significantly influences the freezability of Asian elephant semen. Prefreeze motility, viability, semen volume, semen $\mathrm{pH}$, sperm concentration and the incidence of sperm mid-piece and tail abnormalities all significantly $(\mathrm{p}<0.05)$ affected post-thaw semen quality. While extender and cryoprotectant did not significantly affect any of the above semen quality parameters post-thaw, the skim-milk based extender (INRA96 ${ }^{\circledR}$ ) preserved DNA integrity better $(\mathrm{p}<0.05)$ than the egg yolk extender (TEST). Considerable between-ejaculate variation in all postthaw semen quality parameters was also noted. It is concluded that strict criteria for semen quality is essential for the selection of Asian elephant bull ejaculates suitable for cryopreservation; stricter initial selection should improve the mean post-thaw quality.
\end{abstract}

Keywords: semen cryopreservation; freezability; Asian elephant semen; semen quality 


\section{Introduction}

In1972 the Convention on International Trade in Endangered Species of wild fauna and flora (CITES) listed the Asian elephant (Elephas maximus indicus) in Appendix I; in 2012 the International Union of Conservation of Nature (IUCN) again included this species in the endangered group of the Red List of Threatened Species, reflecting its continued vulnerability to extinction in the wild. Although captive populations have been established and maintained, they are not currently considered sustainable due to a combination of factors, including the risk of inbreeding within the geographically isolated populations, low fertility, unbalanced sex ratios and high infant mortality. Artificial insemination (AI) techniques have been developed in an attempt to facilitate genetic management (Saragusty et al., 2009; Thongtip et al., 2009), and are relatively successful when using fresh or chilled semen (Schmitt et al., 2001). In addition, African elephant semen has been cryopreserved successfully, and this encouraged attempts to cryopreserve Asian elephant semen using the same extenders. Unfortunately, the post-thaw quality of cryopreserved Asian elephant semen proved to be very low, and relatively few bulls were capable of providing semen able to adequately survive the freezing process (Graham et al., 2004; Thongtip et al., 2004; Sa-Ardrit et al., 2006; Saragusty et al., 2009). While post-thaw semen quality depends on a variety of factors, fresh semen quality is used as one of the primary indicators of suitability for semen cryopreservation in many species; in particular, the percentage of motile sperm is a widely used criterion for selecting semen samples prior to freezing (Isachenko et al., 2004; Saragusty et al., 2009; Akhter et al., 2010; Stoops et al., 2010). In some species (e.g. the dog), however, it has been reported that the percentage of progressively motile and morphological normal spermatozoa in fresh semen do not correlate well with the percentage of motile sperm post-thaw (Nöthling et al., 1997). On the other hand, semen volume, sperm concentration and the percentage of morphologically normal sperm in fresh ejaculates have been proposed as useful parameters for selecting (caprine) semen samples for freezing (Dorado et al., 2010), and the same authors also reported that the percentages of motile sperm and sperm with abnormal morphology, in particular acrosome damage, in fresh semen were the best predictors of suitability for freezing (Dorado et al., 2009). Similarly, the proportion of spermatozoa with damaged plasma membranes (often termed "non-viable") in fresh semen has been reported to best predict the proportion of stallion spermatozoa with membrane damage after freezing and thawing (Vidament et al., 1998). However, the most informative fresh semen parameters for predicting post-thaw semen quality may well differ between species.

Extender composition is another factor that plays a significant role in the success of sperm cryopreservation (Salamon and Maxwell, 2000). In general, the components of a sperm cryopreservation extender include a non-permeating cryoprotectant, a penetrating cryoprotectant, a buffer, one or more sugars, salts and antibiotics (Evans and Maxwell, 1987). The earliest reports 
on the cryopreservation of Asian elephant sperm described the use of egg-yolk as the nonpermeating cryoprotectant and glycerol as the penetrating cryoprotectant (Thongtip et al., 2004; Saragusty et al., 2009). Recent studies have indicated that skim-milk powder is an equally effective non-permeating cryoprotectant for Asian elephant sperm (Saragusty et al., 2009). Although glycerol is a widely used, and useful, permeating cryoprotectant for sperm cryopreservation, several authors have reported toxic or apparently contraceptive effects of glycerol included in the inseminate (reviewed by Fahy et al., 1990). The results from pilot fertility trials in stallions indicated that using amides as penetrating cryoprotectants may help to avoid the postulated contraceptive effects of higher concentrations of glycerol. Due to their lower viscosity and low molecular weight, the amides may also inflict less osmotic damage on spermatozoa (Alvarenga et al., 2005).

The aim of the current study was to examine the influence of fresh semen quality and extender composition on the ability of Asian elephant spermatozoa to survive cryopreservation. Semen volume, $\mathrm{pH}$ and concentration and the percentages of motile, viable, and morphologically normal spermatozoa were analyzed in fresh semen and used to categorize ejaculates into quality groups. TEST (egg-yolk based) and INRA96 ${ }^{\circledR}$ (skim-milk based) extenders in combination with glycerol or methylformamide (an amide) as cryoprotectant were used to evaluate the relative effects of different types of non-permeating and permeating cryoprotectants on the ability of sperm to survive cryopreservation. Following freezing and thawing, the DNA fragmentation index, and the dynamics of DNA fragmentation were also evaluated, using the sperm chromatin dispersion test. As sperm DNA stability tends to be disturbed during or after cryopreservation, especially in terms of the dynamics of sperm DNA fragmentation (SDF) (Lopez-Fernandez et al., 2007; 2008), SDF is considered to be a very informative parameter for assessing post-thaw semen quality. The sperm chromatin dispersion test involves an uncomplicated and inexpensive protocol for SDF (de la Torre et al., 2007) such that this test is appropriate for use with wild animal species. Finally, analyses were performed to determine which pre-freeze characteristics best predicted adequate freezability.

\section{Materials and methods}

\section{Chemicals}

All reagents were purchased from Sigma Chemical Company (Sigma, St. Louis, MO, USA) unless otherwise stated.

\section{Semen collection and evaluation}

Semen was collected from seven Asian elephant bulls (Elephas maximus indicus) during October 2009 - January 2010 at the National Elephant Institute (NEI), Lampang, Thailand (latitude 
$18^{\circ} 21.60^{\prime} \mathrm{N}$ and longitude $99^{\circ} 14.92^{\prime} \mathrm{E}$ ). During the semen collection period bulls were not used for natural breeding. Semen collection was performed by per rectum massage of the ampullae as described by (Schmitt and Hildebrandt, 1998). The semen was recovered into sequential 50-ml tubes covered with an opaque cloth bag and attached to a long stick for ease of handling. Immediately after collection, each ejaculate was evaluated for volume, $\mathrm{pH}$, sperm concentration, and the percentages of motile, viable and morphologically normal and abnormal sperm.

Sperm concentration was assessed using a haemocytometer (Bane, 1952), and the percentage of motile sperm was evaluated using a phase-contrast microscope at a magnification of x200 to examine a standardized $10 \mu \mathrm{l}$ drop of semen pipetted onto a pre-warmed $\left(38^{\circ} \mathrm{C}\right)$ glass slide and covered with a cover-slip Sperm viability was estimated using eosin-nigrosin staining (Björndahl et al., 2003), and only ejaculates with more than $50 \%$ viable sperm and no evidence of urine contamination (colour, smell, $\mathrm{pH}$ ) were used for the cryopreservation studies. From the seven bulls initially included in this study, we obtained a total of 28 ejaculates; however, using the above criteria only 9 ejaculates from 3 bulls ( 3 ejaculates from each of 3 bulls) were considered to be of sufficient quality for cryopreservation.

Sperm morphology was evaluated using a protocol developed by Sarder (2008). Smears of fresh semen were air-dried and fixed in absolute alcohol for 3 min and then stained with William's stain for 5 min. The William's stain was prepared from stock solutions I, II and III. Stock solution I consisted of $10 \mathrm{~g}$ basic fuchsin and $95 \%$ alcohol. Stock solution II was a saturated bluish eosin in $95 \%$ alcohol. Stock solution III consisted of $10 \mathrm{ml}$ stock solution I and $170 \mathrm{ml}$ of 5\% phenol. $25 \mathrm{ml}$ of Stock solution II and $50 \mathrm{ml}$ of stock solution III were mixed to produce the final staining solution, which was filtered before use (Sarder, 2008). After staining, the slides were washed in running tap water, dried and examined using bright field light microscopy at a magnification of x1000. 200 spermatozoa per sample were examined for primary (head abnormality) and secondary sperm abnormalities (mid-piece abnormality and tail abnormality), or classified as having normal morphology.

\section{Extenders and cryoprotectants}

Two extenders were selected for this study; INRA96 ${ }^{\circledR}$, a skimmed milk based extender (IMV Technologies, L'Aigle, France), and TEST an egg yolk based extender (Thongtip et al., 2004). INRA $96^{\circledR}$ is a commercial extender used for both chilled and frozen storage of sperm. The INRA96 ${ }^{\circledR}$ was supplemented with $2 \%$ (v/v) egg yolk as described by Pillet et al. (2008). The permeating cryoprotectants trialed were 3\% glycerol, 5\% glycerol and $4 \%$ methylformamide.

Combination of the 2 extenders with the 3 cryoprotectants resulted in 6 freezing media that were tested in this experiment; INRA96 ${ }^{\circledR}+3 \%$ glycerol, INRA96 ${ }^{\circledR}+5 \%$ glycerol, INRA96 ${ }^{\circledR}+4 \%$ methylformamide; TEST $+3 \%$ glycerol, TEST $+5 \%$ glycerol and TEST $+4 \%$ methylformamide. 


\section{Semen freezing and thawing}

Each ejaculate was divided and treated with all six freezing media. Freezing and thawing was performed as described previously by Thongtip et al. (2004). In short, fresh semen was diluted with TEST or INRA96 ${ }^{\circledR}$ to a concentration of 100 x 106 spermatozoa per ml immediately after collection. The diluted semen was cooled to $5{ }^{\circ} \mathrm{C}$ at $1{ }^{\circ} \mathrm{C} / \mathrm{min}$ in a cooling cabinet. Subsequently, an equal volume of extender containing twice the desired final concentration of cryoprotectant (i.e. $6 \%$ glycerol, $10 \%$ glycerol or $8 \%$ methylformamide) was divided into four parts that were added stepwise at 15 minute intervals to the diluted semen, at $5^{\circ} \mathrm{C}$. After complete addition of the freezing extender, the diluted semen (with a final concentration of $50 \times 10^{6}$ spermatozoa per ml) was incubated in a cooling cabinet for a further 1 hour, before the equilibrated semen was loaded into $0.5 \mathrm{ml}$ plastic straws (Kruuse, Ltd., Leeds, UK). The straws were sealed with sealing powder (ARSTM, Chino, CA, USA) and placed on a stainless steel rack that was suspended at $2.5 \mathrm{~cm}$ above liquid nitrogen in a polystyrene box for $10 \mathrm{~min}$. At the end of the $10 \mathrm{~min}$ period in nitrogen vapour, the straws were plunged into liquid nitrogen and stored.

\section{Post-thaw evaluation}

Semen samples were thawed (four straws at a time) by immersing them in a $37{ }^{\circ} \mathrm{C}$ water bath for $30 \mathrm{~s}$; the semen from 4 straws from a single bull-extender-cryoprotectant combination was pooled for subsequent analysis. One milliliter of the sample was used for assessment of viability and acrosome integrity, while the other $1 \mathrm{ml}$ was diluted 1:1 (v:v) with the original extender (without permeating cryoprotectant); INRA96 ${ }^{\circledR}$ or TEST. During evaluation, thawed semen was maintained in a water bath at $37^{\circ} \mathrm{C}$.

Post-thaw sperm motility was assessed subjectively by examining a $10 \mu \mathrm{l}$ droplet of the diluted sample pipetted onto a glass slide and covered with a cover-slip, using a phase-contrast microscope at a magnification of x200. Post-thaw sperm morphology analysis was performed, as previously, on a thin smear of the diluted sample stained with William's stain. The remainder of the diluted part of the sample was incubated in a water bath at $37^{\circ} \mathrm{C}$ and sub-samples were taken for DNA fragmentation analysis after incubation for 0, 4, 8, 24 and $48 \mathrm{~h}$. DNA fragmentation (SDF\%) was analyzed using the SPERM-HALOMAX ${ }^{\circledR}$ kit (Chromacell SL, Madrid, Spain) for sperm chromatin dispersion as described previously (Imrat et al., 2012a); the time points were chosen specifically to examine the dynamics of DNA fragmentation as an additional 'stress test' for sperm quality.

Sperm viability and acrosome integrity were assessed using a modification of the flow cytometric technique described by Thongtip et al. (2004). Briefly, $1 \mathrm{ml}$ of the undiluted thawed sample was mixed with $1 \mathrm{ml}$ of Hepes-buffered modified Tyrode's medium (SP-TALP; $116 \mathrm{mM}$ 
$\mathrm{NaCl}, 20 \mathrm{mM}$ Hepes (pH 7.58), 5.0 mM Glucose, 3.1 mM KCl, $0.4 \mathrm{mM} \mathrm{MgSO} \cdot 7 \mathrm{H} 2 \mathrm{O}, 21.7 \mathrm{mM}$ lactate, $0.3 \mathrm{mM} \mathrm{NaH} 2 \mathrm{PO} 4 \cdot \mathrm{H} 2 \mathrm{O}, 1 \mathrm{mM}$ sodium pyruvate, $2.0 \mathrm{mM} \mathrm{CaCl}$, and $3 \mathrm{mg} / \mathrm{ml} \mathrm{BSA}$; $\mathrm{pH}$ 7.4 ; osmolarity of $300 \mathrm{mOsm} / \mathrm{kg}$ ) and centrifuged at $500 \mathrm{~g}$ for $10 \mathrm{~min}$ at room temperature. The sperm pellet was resuspended with SP-TALP and centrifuged again. The sperm pellet was again resuspended in $1 \mathrm{ml}$ of SP-TALP and adjusted to a concentration of 50 x 106 spermatozoa/ml. For fluorescent labeling, $440 \mu \mathrm{l}$ of the sperm suspension was mixed with $10 \mu \mathrm{lof} 1.25 \mathrm{mg} / \mathrm{ml}$ Propidium Iodide (PI) and $50 \mu \mathrm{l}$ of $0.1 \mathrm{mg} / \mathrm{ml}$ Fluorescein isothiocyanate (FITC)-conjugated peanut agglutinin (PNA; Arachis hypogaea) (FITC-PNA) and incubated at $37^{\circ} \mathrm{C}$ for 30 min in a light-tight box. Before flow cytometric analysis, the stained samples were filtered through a 41 mm nylon mesh (Spectrum, Los Angeles, CA) to remove cell debris and extender particles.

Stained sperm suspensions were examined using a FACS vantage flow cytometer (Becton Dickinson, San Jose, CA) as described by Thongtip et al. (2004). The two dyes were excited in the flow cytometer using a 488-nm argon ion laser (Coherent Innova, Palo, Alto, CA) with $80 \mathrm{~mW}$ laser power. Nonviable spermatozoa would be PI positive and their red fluorescence signal could then be detected using fluorescence detector 2 (FL2) with a $560 \mathrm{~nm}$ short-pass dichroic mirror in the emission pathway, and measured using a band-pass filter of 575/15 nm. Acrosome damaged spermatozoa would become FITC-PNA positive and the resulting green fluorescence could be detected using fluorescence detector 1 (FL1), and measured using a band-pass filter of 530/30 nm. Non-sperm events were gated out of the analyses on the basis of the forward scatter (FSC) and side scatter (SSC) properties that indicated particles with the size and granularity of sperm cells, respectively (scatter-gated sperm analysis). 10000 events from each sample were recorded at 500-1000 events/s and analysed using WinMDI version 2.8 (J. Trotter, http://facs.scripps.edu /software.html).

\section{Statistical analysis}

Coefficients of Variation (CV) for the data for fresh semen parameters was calculated using the equation: $\mathrm{CV}=$ Standard Deviation (S.D.)/Mean. To analyze the predictive value of fresh semen parameters on post-thaw semen quality, simple and multiple linear regression analyses were used. Fresh semen parameters were set as independent variables (X variables) and post-thaw semen parameters were used as dependent variables (Y variables). Normality of distribution of X and $\mathrm{Y}$ variables and residual of regression models were analyzed using the Kolmogorov-Smirnov test. Logarithmic transformation was used when $\mathrm{X}$ and/or $\mathrm{Y}$ variables did not show a normal distribution and the residuals did not show the homoscedasticity. In this respect, the fresh semen volume data and the post-thaw mid-piece abnormality data were log transformed. After transformation, the post-thaw percentage of motile sperm did not meet the normality criteria and therefore logistic regression was used to test the predictive value of fresh semen parameters on the absence ( $0 \%$ motility) or presence $(>0 \%$ motility) of sperm movement post-thaw. Alkaline Information Criterion (AIC) and 2 Log Likelihood (using the Hosmer and Lemeshow test) were 
used as criteria in linear and logistic regression analyses, respectively, for choosing the best model for regression. A generalized linear model (GLM) was used to examine the effects of bull, ejaculate, extender, cryoprotectant and the interaction between extender and cryoprotectant on post-thaw semen parameters, with the exception of post-thaw motility. Kruskal-Wallis' test was used for comparing post-thaw motility results between bulls, ejaculates and the six freezing media $\left(\right.$ INRA96 ${ }^{\circledR}+3 \%$ glycerol, INRA96 ${ }^{\circledR}+5 \%$ glycerol, INRA96 ${ }^{\circledR}+4 \%$ methylformamide; TEST + $3 \%$ glycerol, TEST $+5 \%$ glycerol and TEST $+4 \%$ methylformamide). The Y-axis intercepts and the slope of the DNA fragmentation dynamic curves were calculated from the regression equation ( $\mathrm{X}=$ time during $37^{\circ} \mathrm{C}$ incubation, and $\mathrm{Y}=\mathrm{SDF} \%$ ). The $\mathrm{Y}$-axis intercepts of the DNA fragmentation curves were taken to indicate overall differences in the incidence of sperm DNA fragmentation (1$\mathrm{SDF}$ ), whereas differences in the slope of the line indicated differences in the rate (dynamics) of sperm DNA fragmentation (r-SDF) during incubation at $37^{\circ} \mathrm{C}$. All statistical tests were performed using SPSS 17.0 for Windows (SPSS Inc., Chicago, IL, USA).

\section{Results}

Fresh semen

Descriptive data for fresh semen quality are presented in Table1. None of the ejaculates presented sperm head defects and this parameter is therefore not displayed in the table. Differences were apparent between and within bulls for most parameters, in particular for semen volume, and the percentages of motile spermatozoa and tail abnormalities (over all CV $=1.32,0.70$ and 0.83, respectively). Low deviation between and within bulls was apparent for $\mathrm{pH}$ and the percentage of sperm with normal morphology (overall $\mathrm{CV}=0.07$ and 0.09 , respectively). While the percentage of viable spermatozoa from all selected ejaculates was higher than $50 \%$ (by definition since this was a selection criterion), the percentage of motile spermatozoa achieved a similar threshold for only three of the nine ejaculates (B1.3, B3.2 and B3.3). By contrast, the percentage of spermatozoa with normal morphology was consistently high $(>70 \%)$ in all ejaculates. 
Table 1 Sperm quality parameters for freshly collected semen from 3 Asian elephant bulls (3 ejaculates per bull) with coefficient of variation for each bull (CV1, CV2 and CV3) and for all bulls (CV).

\begin{tabular}{|c|c|c|c|c|c|c|c|c|c|c|c|c|c|c|}
\hline \multirow[t]{2}{*}{ Parameters } & \multicolumn{4}{|c|}{ Bull1 } & \multicolumn{4}{|c|}{ Bull2 } & \multicolumn{4}{|c|}{ Bull3 } & \multirow{2}{*}{$\begin{array}{c}\text { Mean } \pm \text { S.E.M. } \\
(\mathrm{N}=9)\end{array}$} & \multirow{2}{*}{$\mathrm{CV}$} \\
\hline & B1.1 & B1.2 & B1.2 & CV1 & B2.1 & B2.2 & B2.3 & CV2 & B3.1 & B3.2 & B3.2 & $\mathrm{CV} 3$ & & \\
\hline Volume (ml) & 11 & 6.5 & 5 & 0.42 & 12 & 3 & 3 & 0.87 & 62 & 21 & 5 & 1.00 & $14.3 \pm 6.3$ & 1.32 \\
\hline $\mathrm{pH}$ & 7 & 8 & 7.75 & 0.07 & 8 & 8 & 7.46 & 0.04 & 6.85 & 7.05 & 8.12 & 0.09 & $7.6 \pm 0.2$ & 0.07 \\
\hline $\begin{array}{l}\text { Concentration (x } 10^{6} \\
\text { sperms } / \mathrm{ml})\end{array}$ & 1070 & 555 & 685 & 0.35 & 1940 & 1970 & 1290 & 0.22 & 760 & 1610 & 360 & 0.70 & $1137.8 \pm 200.0$ & 0.53 \\
\hline$\%$ Motile & 20 & 5 & 70 & 1.15 & 5 & 40 & 50 & 0.83 & 30 & 70 & 60 & 0.39 & $38.2 \pm 8.9$ & 0.70 \\
\hline$\%$ Viable & 62.5 & 68 & 88 & 0.18 & 62 & 59 & 69 & 0.08 & 52.5 & 87 & 68 & 0.25 & $68.4 \pm 4.0$ & 0.17 \\
\hline $\begin{array}{l}\% \text { Normal } \\
\text { morphology }\end{array}$ & 96.5 & 83.5 & 90.5 & 0.07 & 83.5 & 72 & 84.5 & 0.09 & 83.5 & 96.5 & 82 & 0.09 & $85.8 \pm 2.6$ & 0.09 \\
\hline $\begin{array}{l}\% \text { Mid-piece } \\
\text { abnormality }\end{array}$ & 2.5 & 1 & 2 & 0.42 & 2 & 0 & 2.5 & 0.88 & 1 & 0.5 & 1 & 0.35 & $1.4 \pm 0.3$ & 0.64 \\
\hline$\%$ Tail abnormality & 1.5 & 8.5 & 4 & 0.76 & 8.5 & 24 & 7.5 & 0.69 & 6.5 & 1.5 & 12 & 0.79 & $8.2 \pm 2.3$ & 0.83 \\
\hline$\%$ Detached head & 0 & 8 & 3 & 1.10 & 5.5 & 3 & 6 & 0.33 & 9 & 1.5 & 5 & 0.73 & $4.6 \pm 1.0$ & 0.65 \\
\hline
\end{tabular}


Table 2 Results of simple regression analysis using $\mathrm{p}<0.05$ and fresh semen parameters as independent variables $(\mathrm{X})$ and post-thaw semen parameters as dependent variables $(\mathrm{Y})$. The direction of the regression slope is shown together with the p-value as positive (+) or negative (-).

\begin{tabular}{|c|c|c|c|c|}
\hline Post-thaw (Y) & Fresh $(\mathrm{X})$ & R square & $\mathrm{F}$ & $p$-value \\
\hline \multirow[t]{2}{*}{$\%$ Motile* } & $\mathrm{pH}$ & 0.168 & 9.942 & $0.002(-)$ \\
\hline & Motile & 0.403 & 27.853 & $0.000(+)$ \\
\hline \multirow[t]{5}{*}{$\%$ Viable } & Volume** & 0.271 & 19.356 & $0.000(-)$ \\
\hline & $\mathrm{pH}$ & 0.109 & 6.388 & $0.015(+)$ \\
\hline & Concentration & 0.117 & 6.87 & $0.011(-)$ \\
\hline & Motile & 0.073 & 4.099 & $0.048(+)$ \\
\hline & Viable & 0.095 & 5.467 & $0.023(+)$ \\
\hline \multirow[t]{5}{*}{ \% Live, acrosome intact } & Volume** & 0.274 & 19.579 & $0.000(-)$ \\
\hline & $\mathrm{pH}$ & 0.113 & 6.624 & $0.013(+)$ \\
\hline & Concentration & 0.115 & 6.787 & $0.012(-)$ \\
\hline & Motile & 0.078 & 4.385 & $0.041(+)$ \\
\hline & Viable & 0.098 & 5.646 & $0.021(+)$ \\
\hline \multirow[t]{2}{*}{ \% Normal morphology } & Motile & 0.266 & 18.887 & $0.000(-)$ \\
\hline & Mid-piece abnormality & 0.104 & 6.042 & $0.017(+)$ \\
\hline \multirow[t]{3}{*}{$\%$ Mid-piece abnormality** } & Volume** & 0.275 & 19.359 & $0.000(-)$ \\
\hline & $\mathrm{pH}$ & 0.094 & 5.321 & $0.025(+)$ \\
\hline & Mid-piece abnormality & 0.130 & 7.654 & $0.008(+)$ \\
\hline \multirow[t]{4}{*}{$\%$ Tail abnormality } & Concentration & 0.094 & 5.418 & $0.024(-)$ \\
\hline & Motile & 0.247 & 17.072 & $0.000(+)$ \\
\hline & Viable & 0.086 & 4.914 & $0.031(+)$ \\
\hline & Mid-piece abnormality & 0.099 & 5.725 & $0.020(-)$ \\
\hline \multirow[t]{3}{*}{$\%$ Detached head } & Viable & 0.212 & 13.980 & $0.000(-)$ \\
\hline & Normal morphology & 0.226 & 15.217 & $0.000(-)$ \\
\hline & Tail abnormality & 0.261 & 18.357 & $0.000(+)$ \\
\hline r-SDF & Volume** & 0.113 & 6.629 & $0.013(-)$ \\
\hline \multirow[t]{3}{*}{$1-\mathrm{SDF}$} & Volume** & 0.189 & 12.098 & $0.001(-)$ \\
\hline & $\mathrm{pH}$ & 0.264 & 18.621 & $0.000(+)$ \\
\hline & Concentration & 0.087 & 4.946 & $0.031(+)$ \\
\hline
\end{tabular}

*Only \%motile post-thaw was examined using logistic regression analysis; R square $\sim$ Cox \& Snell R2 and F Chisquare. $* * \%$ mid-piece abnormality in post-thaw semen and fresh semen volume were transformed using logarithmic function before analysis by simple regression. 


\section{Post-thaw semen quality}

\section{Effect of fresh semen parameters on post-thaw semen quality}

Table 2 shows the significant $(\mathrm{p}<0.05)$, but mostly weak, relationships between fresh semen parameters and post-thaw semen quality (one independent variable) detected using regression tests. The percentage of motile sperm in fresh semen significantly influenced the percentage motile post-thaw $\left(\mathrm{R}^{2}=0.40\right)$ but showed only weak relationships with viability $\left(\mathrm{R}^{2}=\right.$ $0.07)$, live spermatozoa with intact acrosomes $\left(R^{2}=0.08\right)$, normal morphology $\left(R^{2}=0.27\right)$ and tail abnormalities $\left(\mathrm{R}^{2}=0.25\right)$. Fresh semen volume had similar and significant relationships with the percentage of viable spermatozoa post-thaw $\left(R^{2}=0.27\right)$, live spermatozoa with intact acrosomes $\left(\mathrm{R}^{2}=0.27\right)$, and mid-piece abnormalities $\left(\mathrm{R}^{2}=0.28\right)$, but was largely uncorrelated with the DNA fragmentation effects; $r-S D F\left(R^{2}=0.11\right)$ and l-SDF $\left(R^{2}=0.19\right)$. Fresh semen pH significantly affected the percentage of motile spermatozoa post-thaw $\left(R^{2}=0.17\right)$, viable spermatozoa $\left(R^{2}=\right.$ $0.11)$, live spermatozoa with intact acrosomes $\left(R^{2}=0.11\right)$, mid-piece abnormalities $\left(R^{2}=0.09\right)$ and l-SDF $\left(\mathrm{R}^{2}=0.26\right)$. Unexpectedly, the percentage of motile sperm in fresh semen $\left(\mathrm{R}^{2}=0.25\right)$ was positively correlated with the percentage of tail abnormalities post-thaw and was negatively correlated with the percentage of sperm with normal morphology post-thaw $\left(R^{2}=0.27\right)$. The best models (Tables 3 and 4) for predicting the various post-thaw semen quality parameters appeared to involve more than one fresh semen parameter (more than one independent variable) in the model, even though some fresh semen parameters included in the model had not previously been significantly related to post-thaw semen quality. The best model $\left(\mathrm{R}^{2}=0.51\right)$ for predicting postthaw motility involved fresh semen $\mathrm{pH}$, the percentage of motile sperm in fresh semen, sperm viability, and the percentage of detached heads. The probability of the presence of post-thaw motility (post-thaw (P-T) motility > 0\%) could be predicted from the following equation;

$$
\mathrm{P}\left(\mathrm{P}-\mathrm{T} \text { motile }>\frac{0 \%)=e^{[26.527-3.04(\text { fresh } \mathrm{pH})+0.135(\text { fresh \% motile })-0.117 \text { (fresh \% viable) }+0.007 \text { (fresh \% detached head) }]}}{1+e^{[26.527-3.04(\text { fresh } \mathrm{pH})+0.135(\text { fresh \% motile) }-0.117 \text { (fresh \% viable })+0.007 \text { (fresh \% detached head })]}}\right.
$$

where $\mathrm{e}$ is the base of natural logarithms, i.e. approximately 2.71828 .

Several regression models were generated from the data presented here.

The post-thaw percentages of viable sperm and live spermatozoa with an intact acrosome could best be predicted using models including fresh semen volume, concentration and the percentage of viable sperm pre-freeze $\left(\mathrm{R}^{2}=0.44\right)$ : i.e. post-thaw viablity $\%=17.384-7.605(\log$ fresh volume $)-0.004$ (fresh concentration) $+0.089(\%$ viable $)$; and $\%$ post-thaw live spermatozoa with intact acrosome $=17.1-7.647(\log$ fresh volume $)-0.004($ fresh concentration $)+0.092(\%$ viable). 
For predicting post-thaw percentage of sperm with normal morphology $\left(\mathrm{R}^{2}=0.41\right)$ the best model was: post-thaw $\%$ morphologically normal sperm $=48.121+0.008$ (fresh concentration) 0.272 (fresh \% motile) +5.502 (fresh \% mid-piece abnormality; for sperm with tail abnormalities $\left(\mathrm{R}^{2}=0.39\right)$ the best model was: post-thaw tail abnormality $\%=43.285-0.008($ fresh concentration $)+0.26$ (fresh \% motile $)-5.398$ (fresh \% mid-piece abnormality)

In addition the post-thaw percentage of sperm with mid-piece abnormalities could be predicted using fresh semen volume and percentage of sperm with mid-piece abnormalities in fresh semen using the model $\left(\mathrm{R}^{2}=0.37\right)$ : $\log$ (post-thaw mid-piece abnormality $\left.\%\right)=0.569-0.424(\log$ fresh volume $)+0.129$ (fresh $\%$ mid-piece abnormality). The combination of pre-freeze sperm motility, viability and normal morphology was a good model $\left(\mathrm{R}^{2}=0.44\right)$ to explain the percentage of detached sperm heads after freezing $=26.178+0.076$ (fresh $\%$ motile $)-0.219$ (fresh $\%$ viable) - 0.096(fresh \% normal morphology).

Two fresh semen parameters (semen volume and percentage of motile spermatozoa) were combined for the best model to predict post-thaw r-SDF $\left(\mathrm{R}^{2}=0.22\right)$; i.e. post-thaw $\mathrm{r}-\mathrm{SDF}=2.143$ -0.424 (log fresh volume) -0.006 (fresh \% motile). The best model for predicting post-thaw l-SDF $\left(\mathrm{R}^{2}=0.49\right)$ incorporated fresh semen volume, $\mathrm{pH}$, sperm concentration and the percentage of sperm with mid-piece abnormalities in fresh semen; i.e. post-thaw $1-S D F=-69.356+1.775(\log$ fresh volume $)+14.301($ fresh $\mathrm{pH})+0.007$ (fresh concentration) +5.008 (fresh \% mid-piece abnormality).

\section{Effect of extenders and cryoprotectants}

The percentages of motile, viable and morphologicaly normal sperm, live spermatozoa with intact acrosomes and sperm with mid-piece abnormalities, tail abnormalities or detached heads post-thaw are presented in Table 5. Appreciable percentages of spermatozoa with head abnormalities were not detected in semen samples post-thaw. None of these parameters were significantly affected by extender or cryoprotectant used. However, while the rate of increase in the SDF did not differ between extenders and cryoprotectants, the 1-SDF (figure 1a) in TEST was significantly higher $(\mathrm{p}<0.05)$ than in INRA96 ${ }^{\circledR}$.

\section{Effect of bull and ejaculate}

Percentages of sperm with normal morphology, mid-piece abnormalities and tail abnormalities post-thaw differed significantly $(\mathrm{p}<0.01)$ between bulls. There was also an apparent effect of ejaculate on freezability since significant differences $(\mathrm{p}<0.01)$ between ejaculates were found in all post-thaw semen parameters. Both bull (Figure 1b) and ejaculate effects were also apparent with respect to both the 1-SDF $(\mathrm{p}<0.001)$ and the $\mathrm{r}-\mathrm{SDF}(\mathrm{p}<0.003)$. 
Table 3 The best-fit model from the logistic regression for predicting percentage of motile spermatozoa post-thaw. This model used fresh semen parameters as predictors (independent variables).

\begin{tabular}{l|cccc}
\hline Post-thaw parameter & Best model & $\begin{array}{c}\text { Cox \& } \\
\text { Snell } \mathrm{R}^{2}\end{array}$ & Chi-square & $p$-value \\
\hline \% Motile & $\begin{array}{c}\mathrm{pH}, \% \text { Motile, \% Viable, \% } \\
\text { Detached head }\end{array}$ & 0.511 & 38.645 & 0.000 \\
\hline
\end{tabular}

Table 4 The best-fit models from the multiple linear regressions for predicting post-thaw semen parameters, with the exception of the percentage of motile spermatozoa. These models used fresh semen parameters as predictors (independent variables).

\begin{tabular}{|c|c|c|c|c|}
\hline Post-thaw parameter & Best model & $\mathrm{R}$ square & $\mathrm{F}$ & $p$-value \\
\hline$\%$ Viable & Volume*, Conc. ${ }^{* *}, \%$ Viable & 0.437 & 12.928 & 0.000 \\
\hline$\%$ Live, acrosome intact & Volume*, Conc.**, $\%$ Viable & 0.439 & 13.057 & 0.000 \\
\hline$\%$ Normal morphology & $\begin{array}{l}\text { Conc. }{ }^{* *}, \% \text { Motile, } \% \text { Mid- } \\
\text { piece abnormal }\end{array}$ & 0.408 & 11.483 & 0.000 \\
\hline$\%$ Mid-piece abnormality* & $\begin{array}{l}\text { Volume*, \% Mid-piece } \\
\text { abnormal }\end{array}$ & 0.372 & 14.836 & 0.000 \\
\hline$\%$ Tail abnormality & $\begin{array}{c}\text { Conc. } * *, \% \text { Motile, } \% \text { Mid- } \\
\text { piece abnormal }\end{array}$ & 0.385 & 10.419 & 0.000 \\
\hline$\%$ Detached head & $\begin{array}{c}\% \text { Motile, } \% \text { Viable, } \% \text { Normal } \\
\text { morphology }\end{array}$ & 0.441 & 13.157 & 0.000 \\
\hline $\mathrm{r}-\mathrm{SDF}$ & Volume*, \% Motile & 0.223 & 7.303 & 0.002 \\
\hline $1-\mathrm{SDF}$ & $\begin{array}{l}\text { Volume*, pH, Conc.**, \% Mid- } \\
\text { piece abnormal }\end{array}$ & 0.487 & 11.647 & 0.000 \\
\hline
\end{tabular}


Table 5 Mean \pm S.E.M. post-thaw semen quality for 3 Asian elephant bulls (3 ejaculates per bull). The results are separated on the basis of extender (INRA96® + 2\% egg yolk versus TEST) and permeant cryoprotectant (3\% glycerol (3\% Gly), 5\% glycerol (5\%Gly) and 4\% methylformamide $(4 \% \mathrm{Met}))$. There were no significant differences in semen quality between the six treatments.

\begin{tabular}{|c|c|c|c|c|c|c|c|}
\hline \multirow{2}{*}{ Parameters } & \multicolumn{3}{|c|}{ INRA96 ${ }^{\circledR}+2 \%$ egg yolk } & \multicolumn{3}{|c|}{ TEST } & \multirow{2}{*}{$\begin{array}{c}\text { Mean } \pm \text { S.E.M } \\
(\mathrm{N}=54)\end{array}$} \\
\hline & $3 \%$ Gly & $5 \%$ Gly & $4 \% \mathrm{Met}$ & $3 \%$ Gly & $5 \%$ Gly & $4 \% \mathrm{Met}$ & \\
\hline$\%$ Motile & $1.7 \pm 0.5$ & $3.1 \pm 0.6$ & $3.1 \pm 0.6$ & $2.0 \pm 0.6$ & $2.9 \pm 0.7$ & $3.1 \pm 0.6$ & $2.7 \pm 0.3$ \\
\hline$\%$ Viable & $11.8 \pm 1.4$ & $12.7 \pm 1.7$ & $12.8 \pm 1.3$ & $10.2 \pm 1.8$ & $11.0 \pm 2.7$ & $14.1 \pm 3.0$ & $12.1 \pm 0.8$ \\
\hline$\%$ Live, acrosome intact & $11.5 \pm 1.5$ & $12.6 \pm 1.8$ & $12.6 \pm 1.3$ & $10.1 \pm 1.8$ & $10.9 \pm 2.6$ & $14.1 \pm 3.0$ & $12.0 \pm 0.8$ \\
\hline$\%$ Normal morphology & $56.3 \pm 5.2$ & $56.7 \pm 4.8$ & $46.8 \pm 4.7$ & $61.3 \pm 5.1$ & $59.0 \pm 5.4$ & $49.1 \pm 6.5$ & $54.9 \pm 2.2$ \\
\hline$\%$ Midpiece abnormality & $2.7 \pm 0.5$ & $2.4 \pm 0.4$ & $3.9 \pm 1.2$ & $2.5 \pm 0.5$ & $2.7 \pm 0.6$ & $3.5 \pm 1.0$ & $3.0 \pm 0.3$ \\
\hline$\%$ Tail abnormality & $35.8 \pm 4.9$ & $36.1 \pm 5.0$ & $43.1 \pm 5.6$ & $30.4 \pm 5.0$ & $31.8 \pm 5.7$ & $41.0 \pm 6.1$ & $36.4 \pm 2.2$ \\
\hline$\%$ Detached head & $5.2 \pm 1.0$ & $4.8 \pm 0.9$ & $6.2 \pm 1.4$ & $5.8 \pm 1.5$ & $6.4 \pm 1.3$ & $6.4 \pm 1.0$ & $5.8 \pm 0.5$ \\
\hline
\end{tabular}



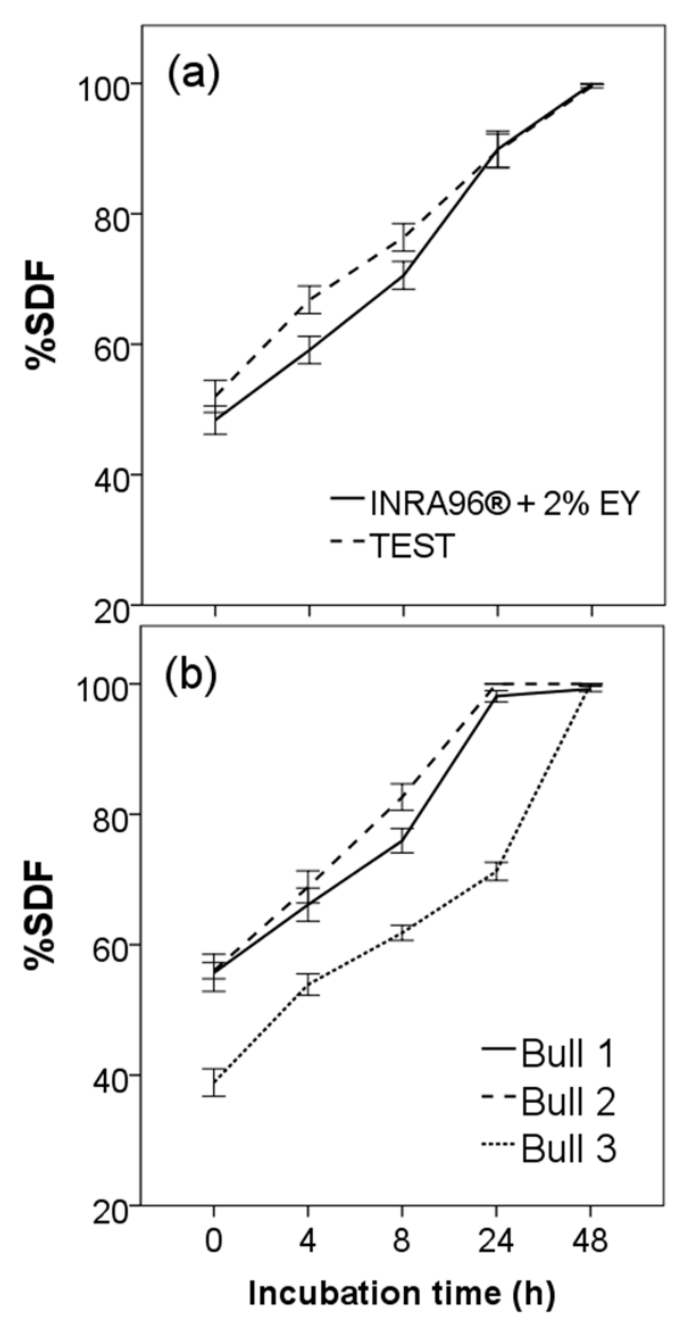

Figure 1 Graphs showing sperm DNA fragmentation dynamics in frozen-thawed Asian elephant sperm; the mean $( \pm$ S.E.M. $)$ percentages of sperm with fragmented DNA (\%SDF) are plotted for $0,4,8,24$ and $48 \mathrm{~h}$ of incubation at $37^{\circ} \mathrm{C}$. The graphs are subsequently divided to show differences between (a) TEST and INRA96 ${ }^{\circledR}$ extenders (b) the three bulls examined.

\section{Discussion}

This study demonstrated that aspects of fresh semen quality such as semen volume, $\mathrm{pH}$, sperm concentration, and percentages of motile, viable and morphologically abnormal sperm have an important impact on the freezability of Asian elephant semen. This supports the widespread, but poorly documented, view that the evaluation of fresh semen quality is helpful in predicting the suitability of semen samples for cryopreservation (Blesbois et al., 2008).

Seminal plasma composition and/or presence have been reported to influence quality of both fresh and frozen semen (Rodríguez-Martínez et al., 2011), possibly through effects on semen $\mathrm{pH}$, volume and concentration. Excessive alkalinity of both bull and ram semen has been related to poor fertility or motility (Mann, 1964), and we previously reported a positive correlation between semen $\mathrm{pH}$ prior to freezing and the proportion of spermatozoa with detached-heads post-thaw (Imrat et al., 2012a), These observations parallel the present findings that high initial semen $\mathrm{pH}$ negatively influences sperm DNA stability post-thaw. Seminal plasma components and volume vary between both individuals and ejaculates because of individual male differences but also as a result of semen collection techniques (Rodríguez-Martínez et al., 2011); this is especially true for semen collection by manual rectal massage in bull elephants since it is almost impossible to obtain the same mix of seminal plasma components in each ejaculate, and there is a high likelihood of urine contamination (Imrat et al., 2012a). Removing seminal plasma has been reported to be useful during preparation of semen for freezing because it helps to ameliorate the detrimental effects of seminal plasma on cryopreserved sperm that have been reported in a range of species (Barbas and Mascarenhas, 2009). In the brown bear for example, centrifugation with a suitable diluent is an important method for 'cleaning' urine-contaminated semen samples before processing for cryopreservation (Nicolas et al., 2012). On the other hand, improper removal of seminal plasma (e.g. high speed centrifugation) may damage spermatozoa 
(Purdy, 2006) and/or lead to loss of an unacceptably high percentage of the sperm (trying to remove too much of the supernatant). Moreover, sperm separation techniques such as swim-up and density gradients that help to select viable spermatozoa and eliminate those with membrane damage, abnormal morphology or DNA damage (Jayaraman et al., 2012) can lead to significant increases in post-thaw semen quality, albeit with a marked decrease in total number of sperm remaining. The high incidence of SDF immediately after thawing semen supports the view that it might be beneficial to add a supplement to protect sperm DNA stability during the semen processing steps. This was confirmed in our previous study (Imrat et al., 2012b), which showed that a DNA-protecting extender was helpful during cooling and storage. However, the initial DNA stability within fresh semen is the primary determinant of SDF in every subsequent cryopreservation step (Imrat et al., 2012a).

Our findings also support the idea that it would be useful to separate Asian elephant sperm populations on the basis of their sperm DNA integrity before freezing. Unexpectedly, high sperm motility and viability in fresh semen tended to result in more spermatozoa with tail defects postthaw (thereby compromising percentage with normal morphology); these effects may be attributable to the hypo-osmotic stresses involved during the freezing-thawing process. This suggests that the acquisition of the tail defect is a response of viable spermatozoa, and therefore that it is induced osmotically, as occurs in the hypo-osmotic swelling test (Stanger et al., 2010). This implies that the diluting process after thawing should be considered as a critically important part of the thawing process. For human spermatozoa, a serial stepwise dilution after thawing limits the increase in sperm volume to a smaller range and therefore improves post-thaw motility from less than $30 \%$ in a single-step dilution to more than $90 \%$ (Critser et al., 1987). It is interesting that unrelated pre-freeze parameters were included in the predictive models for some post-thaw parameters, and that most models needed more than one pre-freeze parameter for the best fit. Furthermore, it is fortunate from a practical point of view that the most informative pre-freeze parameters were those most easily measured; i.e. semen volume, $\mathrm{pH}$, concentration, motility and viability.

In the current study, post-thaw semen quality parameters such as percentages of motile, viable, and morphologically normal spermatozoa, or live spermatozoa with intact acrosomes, and the dynamic DNA damage responses did not differ between extenders or cryoprotectants, with one exception; the SDF in INRA96 ${ }^{\circledR}$ was lower than that in TEST. However, poor maintenance of both viability and the percentage of motile spermatozoa were recorded for both extenders and for both permeating cryoprotectants (glycerol and methylformamide). We had hoped that using an amide cryoprotectant such as methylformamide with a lower molecular weight and viscosity than glycerol, would reduce the cellular damage presumably caused by osmotic stress (Dalimata and Graham, 1997; Ball and Vo, 2001), however this was not demonstrated. Neither was there any significant difference between $3 \%$ and $5 \%$ glycerol with regard to post-thaw semen quality. In this respect, Saragusty et al. (2009) reported that $2.5 \%$ glycerol and $15 \%$ glycerol were, respectively, too low and too high for cryopreserving Asian elephant spermatozoa, but that there was little effect 
of concentration in between these extremes; they recommended using $4 \%$ glycerol for cryopreserving Asian elephant sperm. On the side of caution, while post-thaw sperm motility is often very good after cryopreservation with a medium containing a high percentage of glycerol (e.g. >7\% glycerol: (Robbins et al., 1976), high concentrations of glycerol have been reported to negatively affect fertility (Barbas and Mascarenhas, 2009).

Species differences have a major impact on the survival of spermatozoa during cryopreservation, and the cryoprotectants most appropriate for protecting against cell damage; this has been attributed to differences in sperm membrane composition and the way in which the membrane changes during the cooling process (reviewed by Loomis and Graham, 2008). It is therefore essential to develop species-specific cryopreservation protocols (Holt, 2000). The skim milk extender, INRA96 ${ }^{\circledR}$, has proven to be useful for maintaining post-thaw quality of stallion semen and for preserving fertility potential after AI with frozen-thawed semen (Fayrer-Hosken et al., 2008; Pillet et al., 2008). In the current study with Asian elephant sperm, INRA96 ${ }^{\circledR}$ supplemented with $2 \%$ (v/v) egg yolk was slightly better than the egg yolk extender, TEST, for maintaining sperm DNA stability post-thaw; otherwise, there was little to choose between the two base media. However, it is possible that, as for stallions (Loomis and Graham, 2008), semen from individual elephant bulls may preserve better in one extender than the other and that initial trials are required to determine the most desirable cryopreservation diluent for a given bull.

Certainly, our results showed between bull and ejaculate differences in semen freezability, as previously noted for other species (Watson, 1995). These may, in part, explain why the absolute levels of post-thaw semen quality in this study were low, despite using general techniques that had yielded better mean results in a previous study (Thongtip et al., 2009). Differences in post-thaw semen quality between males and between ejaculates from a specific male have been reported for many species (Neild et al., 2003; Garde et al., 2008; Lopes et al., 2009; Dorado et al., 2010). The dairy cattle industry has selected bulls for AI that deliver spermatozoa able to withstand standard cryopreservation protocols well. Consequently, semen cryopreservation techniques in the dairy cattle industry have become more uniform (Loomis and Graham, 2008); in effect, the animals have been selected to fit the system, rather than vice versa. This situation differs significantly to that for Asian elephant bulls in Thailand, where selection for a specific trait (such as ability of spermatozoa to withstand a predetermined semen cryopreservation protocol) would be detrimental to the overall aim of the conservation program, i.e. preserving as much genetic diversity as possible. Cryopreservation protocols that are only suitable for a single bull or a small subset of bulls do not fulfill the goal of helping to establish gene banks for this species, because they lead to the rejection of too many bulls or ejaculates. In this respect, Saragusty et al. (2009) rejected semen from five of the six bulls that they studied, while Kiso et al. (2011) only used ten of the seventy five ejaculates that they collected. In terms of genetic management and conservation, every bull and every ejaculate should be regarded as valuable and every effort should be made to avoid discarding them. In this respect, the aim should be to develop a cryopreservation protocol (or panel of 
interchangeable protocols) that offers a reasonable likelihood of being able to preserve semen from as large as possible a range of fertile bulls.

In conclusion, we have shown that aspects of fresh semen quality are important for predicting the success of semen cryopreservation for Asian elephant bull semen. Moreover, because there is considerable variation in freezability between individual bulls and ejaculates, specific protocols will need to be developed for the species as a whole (e.g. see Saragusty et al. (2009)) but tailored to suit individual bulls. These individually tailored protocols concern not only which media and cryoprotectants to use, but also how to improve collection protocols to reduce the influence of urine contamination and differences in seminal plasma composition, sperm concentration and initial semen quality. For example, the high rate of non-viable spermatozoa and parallel high incidence of DNA fragmented spermatozoa post-thaw suggests that there may be some value in adding antioxidants to cryopreservation media and implementing a routine sperm 'washing' step by cushioned centrifugation, as described by Saragusty et al. (2009).

\section{Acknowledgements}

The authors thank the EU-Asia-Link Project on "Managing the Health and Reproduction of Elephant Population in Asia" TH/Asia Link/012 (9141055) for providing the funds for Podjana Imrat's PhD scholarship and the described studies. We also thank the staff at the National Elephant Institute (NEI), Lampang, Thailand for their support and the Institute of Molecular Biosciences, Mahidol University, Nakhonpathom for access to the flow cytometer.

\section{References}

Akhter S, Ansari MS, Rakha BA, Andrabi SMH, Iqbal S, Ullah N, 2010. Cryopreservation of buffalo (Bubalus bubalis) semen in Bioxcell@ extender. Theriogenology 74(6): 951-955.

Alvarenga MA, Papa FO, Landim-Alvarenga FC, Medeiros CM, 2005. Amides as cryoprotectants for freezing stallion semen: A review. Anim Reprod Sci 89(1-4): 105-113.

Ball BA, Vo A, 2001. Osmotic tolerance of equine spermatozoa and the effects of soluble cryoprotectants on equine sperm motility, viability and mitochondrial membrane potential. J Androl 22(6): 1061-1069.

Bane A, 1952. A study on the technique of hemocytometric determination of sperm motility and sperm concentration in bull semen. Cornell Vet 42(4): 518-531.

Barbas JP, Mascarenhas RD, 2009. Cryopreservation of domestic animal sperm cells. Cell Tissue Bank 10(1): 49-62.

Björndahl L, Söderlund I, Kvist U, 2003. Evaluation of the one-step eosin-nigrosin staining technique for human sperm vitality assessment. Hum Reprod 18(4): 813-816.

Blesbois E, Grasseau I, Seigneurin F, Mignon-Grasteau S, Saint Jalme M, Mialon-Richard MM, 2008. Predictors of success of semen cryopreservation in chickens. Theriogenology 69(2): 252-261.

Critser JK, Arneson BW, Aaker DV, Huse-Benda AR, Ball GD, 1987. Cryopreservation of human spermatozoa. II. Postthaw chronology of motility and of zona-free hamster ova penetration. Fertil Steril 47(6): 980-984.

Dalimata AM, Graham JK, 1997. Cryopreservation of rabbit spermatozoa using acetamide in combination with trehalose and methylcellulose. Theriogenology 48(5): 831-841. 
de la Torre J, Lopez-Fernandez C, Pita M, Fernandez JL, Johnston SD, Gosalvez J, 2007. Simultaneous observation of DNA fragmentation and protein loss in the boar spermatozoon following application of the sperm chromatin dispersion (SCD) test. J Androl 28(4): 533-540.

Dorado J, Hidalgo M, Muñoz A, Rodríguez I, 2009. Assessment of goat semen freezability according to the spermatozoa characteristics from fresh and frozen samples. Anim Reprod Sci 112(1-2): 150-157.

Dorado J, Mũnoz-Serrano A, Hidalgo M, 2010. The effect of cryopreservation on goat semen characteristics related to sperm freezability. Anim Reprod Sci 121(1-2): 115-123.

Evans G, Maxwell W, 1987. Salamon's artificial insemination of sheep and goats, Butterworth, Sydney. 194 p.

Fahy GM, Lilley TH, Linsdell H, Douglas MSJ, Meryman HT, 1990. Cryoprotectant toxicity and cryoprotectant toxicity reduction: in search of molecular mechanisms. Cryobiology 27(3): 247-268.

Fayrer-Hosken R, Abreu-Barbosa C, Heusner G, Jones L, 2008. Cryopreservation of Stallion Spermatozoa with INRA96 and Glycerol. J Equine Vet Sci 28(11): 672-676.

Garde JJ, del Olmo A, Soler AJ, Espeso G, Gomendio M, Roldan ERS, 2008. Effect of egg yolk, cryoprotectant, and various sugars on semen cryopreservation in endangered Cuvier's gazelle (Gazella cuvieri). Anim Reprod Sci 108(3-4): 384-401.

Graham LH, Bando J, Gray C, Buhr MM, 2004. Liquid storage of Asian elephant (Elephas maximus) sperm at $4{ }^{\circ} \mathrm{C}$. Anim Reprod Sci 80(3-4): 329-340.

Holt WV, 2000. Fundamental aspects of sperm cryobiology: the importance of species and individual differences. Theriogenology 53(1): 47-58.

Imrat P, Hernandez M, Rittem S, Thongtip N, Mahasawangkul S, Gosa'1vez J, Holt WV, 2012a. The dynamics of sperm DNA stability in Asian elephant (Elephas maximus) spermatozoa before and after cryopreservation. Theriogenology 77(5): 998-1007.

Imrat P, Mahasawangkul S, Gosálvez J, Suthunmapinanth P, Sombutputorn P, Jansittiwate S, Thongtip N, Pinyopummin A, Colenbrander B, Holt WV, Stout TAE, 2012b. Effect of cooled storage on quality and DNA integrity of Asian elephant (Elephas maximus) spermatozoa. Reprod Fertil Dev 24(8): 1105-1116.

Isachenko V, Isachenko E, Katkov II, Montag M, Dessole S, Nawroth F, van der Ven H, 2004. Cryoprotectant-free cryopreservation of human spermatozoa by vitrification and freezing in vapor: effect on motility, DNA integrity, and fertilization ability. Biol Reprod 71(4): 1167-1173.

Jayaraman V, Upadhya D, Narayan PK, Adiga SK, 2012. Sperm processing by swim-up and density gradient is effective in elimination of sperm with DNA damage. J Assist Reprod Genet 29(6): 557-563.

Kiso WK, Brown JL, Siewerdt F, Schmitt DL, OLSON D, Crichton EG, Pukazhenthi BS, 2011. Liquid semen storage in elephants (Elephas maximus and Loxodonta africana): species differences and storage optimization. J Androl 32(4): 420-431.

Loomis PR, Graham JK, 2008. Commercial semen freezing: Individual male variation in cryosurvival and the response of stallion sperm to customized freezing protocols. Anim Reprod Sci 105(1-2): 119-128.

Lopes KRF, Costa LLM, Lima GL, Souza ALP, Silva AR, 2009. Dimethylformamide is no better than glycerol for cryopreservation of canine semen. Theriogenology 72(5): 650-654.

Lopez-Fernandez C, Crespo F, Arroyo F, Fernandez JL, Arana P, Johnston SD, Gosalvez J, 2007. Dynamics of sperm DNA fragmentation in domestic animals II. The stallion. Theriogenology 68(9): 1240-1250.

Lopez-Fernandez C, Fernandez JL, Gosalbez A, Arroyo F, Vazquez JM, Holt WV, Gosalvez J, 2008. Dynamics of sperm DNA fragmentation in domestic animals III. Ram. Theriogenology 70(6): 898-908. 
Mann T, 1964. The biochemistry of semen and of the male reproductive tract. Methuen, London. $493 \mathrm{p}$.

Neild DM, Gadella BM, Chaves MG, Miragaya MH, Colenbrander B, Agüero A, 2003. Membrane changes during different stages of freeze-thaw protocol for equine semen cryopreservation. Theriogenology 59(8): 16931705.

Nicolas M, Alvarez M, Borragán S, Martinez-Pastor F, Chamorro CA, Alvarez-Rodriguez M, de Paz P, Anel L, 2012. Evaluation of the qualitative and quantitative effectiveness of three media of centrifugation (Maxifreeze, Cushion Fluid Equine, and PureSperm 100) in preparation of fresh or frozen-thawed brown bear spermatozoa. Theriogenology 77(6): 1119-1128.

Nöthling JO, Gerstenberg C, Volkmann DH, 1997. Semen quality after thawing: correlation with fertility and fresh semen quality in dogs. J Reprod Fertil Suppl 51: 109-116.

Pillet E, Batellier F, Duchamp G, Furstoss V, Le Vern Y, Kerboeuf D, Vidament M, Magistrini M, 2008. Freezing stallion semen in INRA96®-based extender improves fertility rates in comparison with INRA82. Daily Sci Technol 88: 257-265.

Purdy PH, 2006. A review on goat sperm cryopreservation. Small Rumin Res 63(3): 215-225.

Robbins RK, Saacke RG, Chandler PT, 1976. Influence of freeze rate, thaw rate and glycerol level on acrosomal retention and survival of bovine spermatozoa frozen in French straws. J Anim Sci 42(1): 145-154.

Rodríguez-Martínez H, Kvist U, Ernerudh J, Sanz L, Calvete JJ, 2011. Seminal plasma proteins: what role do they play? Am J Reprod Immunol 66 (Suppl. 1): 11-22.

Sa-Ardrit M, Saikhun J, Thongtip N, Damyang M, Mahasawangkul S, Angkawanish T, Jansittiwate S, Faisaikarm T, Kitiyanant Y, Pavasuthipaisit K, Pinyopummin A, 2006. Ultrastructural alterations of frozen-thawed Asian elephant (Elephas maximus) spermatozoa. Int J Androl 29(2): 346-352.

Salamon S, Maxwell WM, 2000. Storage of ram semen. Anim Reprod Sci 62(1-3): 77-111.

Saragusty J, Hildebrandt TB, Behr B, Knieriem A, Kruse J, Hermes R, 2009. Successful cryopreservation of Asian elephant (Elephas maximus) spermatozoa. Anim Reprod Sci 115(1-4): 255-266.

Sarder MJU, 2008. Effects of age, body weight, body condition and scrotal circumference on sperm abnormalities of bulls used for artificial insemination (AI) programme in Bangladesh. University Journal of Zoology Rajshahi University 2008 27: 73-78.

Schmitt DL, Hildebrandt TB, 1998. Manual collection and characterization of semen from Asian elephants (Elephas maximus). Anim Reprod Sci 53(1-4): 309-314.

Schmitt DL, Hildebrant TB, Hermes R, Goritz F, 2001. Assisted reproductive technology in elephants, Proc 1st Int Symp Assisted Reproductive Technology for Conservation Genetic Management of Wildlife, Omaha's Henry Doorly Zoo, p. 15-17.

Stanger JD, Vo L, Yovich JL, Almahbobi G, 2010. Hypo-osmotic swelling test identifies individual spermatozoa with minimal DNA fragmentation. Reprod Biomed Online 21(4): 474-484.

Stoops MA, Atkinson MW, Blumer ES, Campbell MK, Roth TL, 2010. Semen cryopreservation in the Indian rhinoceros (Rhinoceros unicornis). Theriogenology 73(8): 1104-1115.

Thongtip N, Mahasawangkul S, Thitaram C, Pongsopavijitr P, Kornkaewrat K, Pinyopummin A, Angkawanish T, Jansittiwate S, Rungsri R, Boonprasert K, Wongkalasin W, Homkong P, Dejchaisri S, Wajjwalkul W, Saikhun K, 2009. Successful artificial insemination in the Asian elephant (Elephas maximus) using chilled and frozen-thawed semen. Reprod Biol Endocrin 7: 75-82.

Thongtip N, Saikhun J, Damyang M, Mahasawangkul S, Suthunmapinata P, Yindee M, Kongsila A, Angkawanish T, Jansittiwate S, Wongkalasin W, Wajjwalkul W, Kitiyanant Y, Pavasuthipaisit K, Pinyopummin A, 2004. Evaluation of post-thaw Asian elephant (Elephas maximus) spermatozoa using flow cytometry: the effects of extender and cryoprotectant. Theriogenology 62(3-4): 748-760. 
Vidament M, Cognard E, Yvon J-M, Sattler M, Palmer E, Magistrini M, 1998. Evaluation of Stallion Semen Before and After Freezing. Reprod Dom Anim 33: 271-277.

Watson PF, 1995. Recent developments and concepts in the cryopreservation of spermatozoa and the assessment of their post-thawing function. Reprod Fertil Dev 7(4): 871-891. 